\title{
Heterozygous VPS13A and PARK2 Mutations in a Patient with Parkinsonism and Seizures
}

\author{
Steven D. Mitchella Roger L. Albin ${ }^{\text {b, c }}$ William T. Dauer ${ }^{d, e}$ \\ John L. Goudreau ${ }^{a} \quad$ Christos Sidiropoulos $^{a}$
}

aDepartment of Neurology, Michigan State University, East Lansing, MI, USA; ${ }^{b}$ Department of Neurology, University of Michigan, Ann Arbor, MI, USA; 'VAAAHS GRECC, Ann Arbor, MI, USA; ${ }^{d}$ Department of Neurology and Neurotherapeutics, O'Donnell Brain Institute, Dallas, TX, USA; 'Department of Neuroscience, University of Texas Southwestern, Dallas, TX, USA

\author{
Keywords \\ Chorea-acanthocytosis - Neuroacanthocytosis - Parkinsonism · PARK2 - Vacuolar protein \\ sorting $13 \mathrm{~A}$
}

\section{Abstract}

Neuroacanthocytosis (NA) is a diverse group of disorders in which nervous system abnormalities co-occur with irregularly shaped red blood cells called acanthocytes. Chorea-acanthocytosis is the most common of these syndromes and is an autosomal recessive disease caused by mutations in the vacuolar protein sorting 13A (VPS13A) gene. We report a case of early onset parkinsonism and seizures in a 43-year-old male with a family history of NA. Neurologic examinations showed cognitive impairment and marked parkinsonian signs. MRI showed bilateral basal ganglia gliosis. He was found to have a novel heterozygous mutation in the VPS13A gene, in addition a heterozygous mutation in the PARK2 gene. His clinical picture was atypical for typical chorea-acanthocytosis (ChAc). The compound heterozygous mutations of VPS13A and PARK2 provide the most plausible explanation for this patient's clinical symptoms. This case adds to the phenotypic diversity of ChAc. More research is needed to fully understand the roles of epistatic interactions on phenotypic expression of neurodegenerative diseases. 
Mitchell et al.: Heterozygous VPS13A and PARK2 Mutations

\section{Introduction}

Neuroacanthocytosis (NA) denotes a diverse group of neurological disorders accompanied by thorn-shaped abnormalities of red blood cell morphology (acanthocytes) [1]. Core NA syndromes are characterized pathologically by basal ganglia degeneration and phenotypically by a variety of movement disorders (e.g., chorea, dystonia, and parkinsonism) along with cognitive impairment, psychiatric symptoms, seizures, and axonal neuropathy [2]. Core NA syndromes include autosomal recessive chorea-acanthocytosis (ChAc), X-linked McLeod syndrome, autosomal dominant Huntington's disease-like 2, and autosomal recessive pantothenate kinase-associated. ChAc, McLeod syndrome, and Huntington's disease-like 2 are usually adult-onset disorders with characteristically slow progression, whereas pantothenate kinase-associated neurodegeneration is usually of childhood or juvenile onset [2].

The most common of the NA syndromes, ChAc is an autosomal recessive condition caused by mutations in the vacuolar protein sorting 13A (VPS13A) gene located on chromosome 9 , which encodes the protein chorein [2]. Disease manifestation typically occurs in early adulthood, usually between ages 20 and 40 [1]. Often, the initial presentation is subtle cognitive or psychiatric symptoms [2]. Seizures are seen in $40 \%$ of ChAc patients [1] and may precede motor symptoms by as much as a decade [2]. During the disease course, most patients develop a characteristic phenotype including chorea, feeding dystonia, orofacial dyskinesias, dysarthria, involuntary tic-like vocalizations, and lip and tongue biting [2]. Limb dystonia is also common, and patients may have a gait characterized by truncal instability and severe trunk spasms [2].

Peripheral nervous system dysfunction in ChAc may lead to diminished or absent reflexes, sensory-motor neuropathy, and variable weakness and atrophy [2]. Autonomic nervous system dysfunction may lead to abnormal respiratory rhythm, orthostatic hypotension, or impaired digestive motility [1]. Serum creatine kinase is elevated in up to $85 \%$ of ChAc patients, and liver enzymes are often elevated as well [1]. Neuroimaging shows atrophy of the caudate nucleus, as well as the putamen and globus pallidus [1,2]. Diagnosis is either by genetic testing or by Western blot detection of chorein protein [1]. Treatment of ChAc is symptomatic, as there are currently no curative or disease-modifying drugs available $[1,2]$. The disease usually slowly progresses over 15-30 years, but sudden death presumably due to seizure or autonomic dysfunction may occur [2].

\section{Case Report}

A 43-year-old man presented for evaluation of parkinsonism. Past medical history was significant for alcohol abuse. Family history was significant for ChAc in 2 sisters, both with typical clinical manifestations of chorea, lip and tongue biting, and cognitive decline. Diagnosis was confirmed in one by Western blot with characteristic loss-of-chorein expression and in the second by neuropathologic analysis (both at Zentrum für Neuropathologie und Prionforschung; Munich, Germany). Both sisters died in their thirties. Of note, his parents had no history of neurologic disease, although their genetic profiles are unknown.

Our patient was initially evaluated at age 36 for obsessive tendencies. Neurologic examination at that time was normal. He was reevaluated at age 40 for arm-hand tremor, incoordination, memory decline, and anxiety. Neurologic examination was notable for mildly masked facies, mild neck retroflexion, bradykinetic, and irregular rapid hand movements, and mild postural and kinetic tremor with questionable low-amplitude involuntary leg movements. Over the next 4 months, he developed recurrent generalized seizures with repeat examination showing progression of his parkinsonism and slightly wide-based gait. MRI brain at age 40 was unremarkable, and topiramate administration resulted in good seizure control.

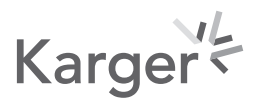


Fig. 1. CT head without contrast at age 44 showing bilateral globus pallidus hypodensities.

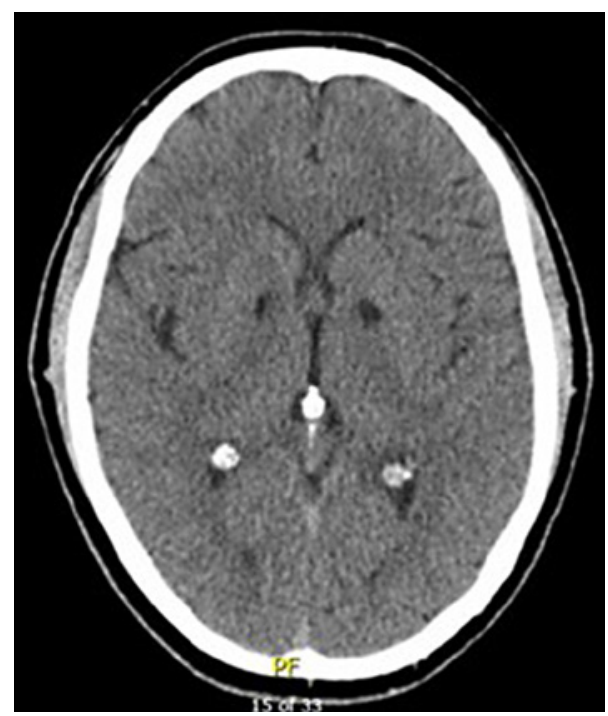

Over the next three years, he developed worsening bradykinesia, bilateral hand rest and action tremor, imbalance, word finding and speech difficulty, and personality change. He denied lip or tongue biting, feeding dystonia, dysphagia, drooling, or anosmia. Neurologic examination revealed moderate hypomimia without evidence of lip or tongue biting. Montreal Cognitive Assessment score was 22/30. Tone was mildly increased in his head, neck, and bilateral arms. He had spasticity in his legs and cogwheel rigidity in both arms symmetrically. Bilateral high-frequency low-amplitude rest tremor was present, exaggerated by action. Alternating movements showed symmetric moderate-to-severe reduction in amplitude and speed in all extremities. Reflexes were equal and symmetric throughout. No focal atrophy or fasciculations were noted. His gait was cautious, with shuffling and reduced arm swing. He had mild unsteadiness with pull testing.

CT head without contrast at age 44 showed globus pallidus hypodensities bilaterally (Fig. 1). MRI brain revealed cystic globus pallidus degeneration with possible hemosiderin deposition bilaterally (Fig. 2). Dopamine transporter scan was normal. Blood tests, including creatine kinase, heavy metal screen, and paraneoplastic autoantibody panel were negative. Peripheral blood smear showed normal red cell morphology, and Western blot analysis on 2 separate occasions showed no chorein protein abnormalities. Twenty-four-hour urine copper levels were normal. A neurodegeneration with brain iron accumulation gene panel (including genes ATP13A2, C19orf12, COASY, CP, DCAF17, FTL, FUCA1, PANK2, PLA2G6, SQSTM1, WDR45, FA2H, KIF1A, and TRIM32) through Invitae (San Francisco, CA, USA) was normal. Whole-exome sequencing through Invitae revealed an exon 2 deletion of the PARK2 gene and a novel but likely pathogenic variant in intron 46 (splice donor c.6095+1 G>A) of the VPS13A gene.

After our evaluation, a trial of carbidopa-levodopa was prescribed. Despite upward titration to levodopa $200 \mathrm{mg}$ three times daily, there was no improvement in his parkinsonism. Propranolol $20 \mathrm{mg}$ three times daily resulted in short-term tremor improvement and is being increased to see if any further benefit can be achieved. Baclofen resulted in decreased spasticity.

\section{Discussion}

Genetic testing in our patient revealed heterozygous mutations in 2 genes associated with recessively inherited movement disorders. Regarding the mutant VPS13A allele, our patient exhibited some ChAc features including cognitive impairment, dysarthria, and seizures 


\section{Case Reports in \\ Neurology}

\begin{tabular}{|c|c|}
\hline \multicolumn{2}{|c|}{ Case Rep Neurol 2021;13:341-346 } \\
\hline DOI: $10.1159 / 000515805$ & $\begin{array}{l}\text { (c) } 2021 \text { The Author(s). Published by S. Karger AG, Basel } \\
\text { www.karger.com/crn }\end{array}$ \\
\hline
\end{tabular}
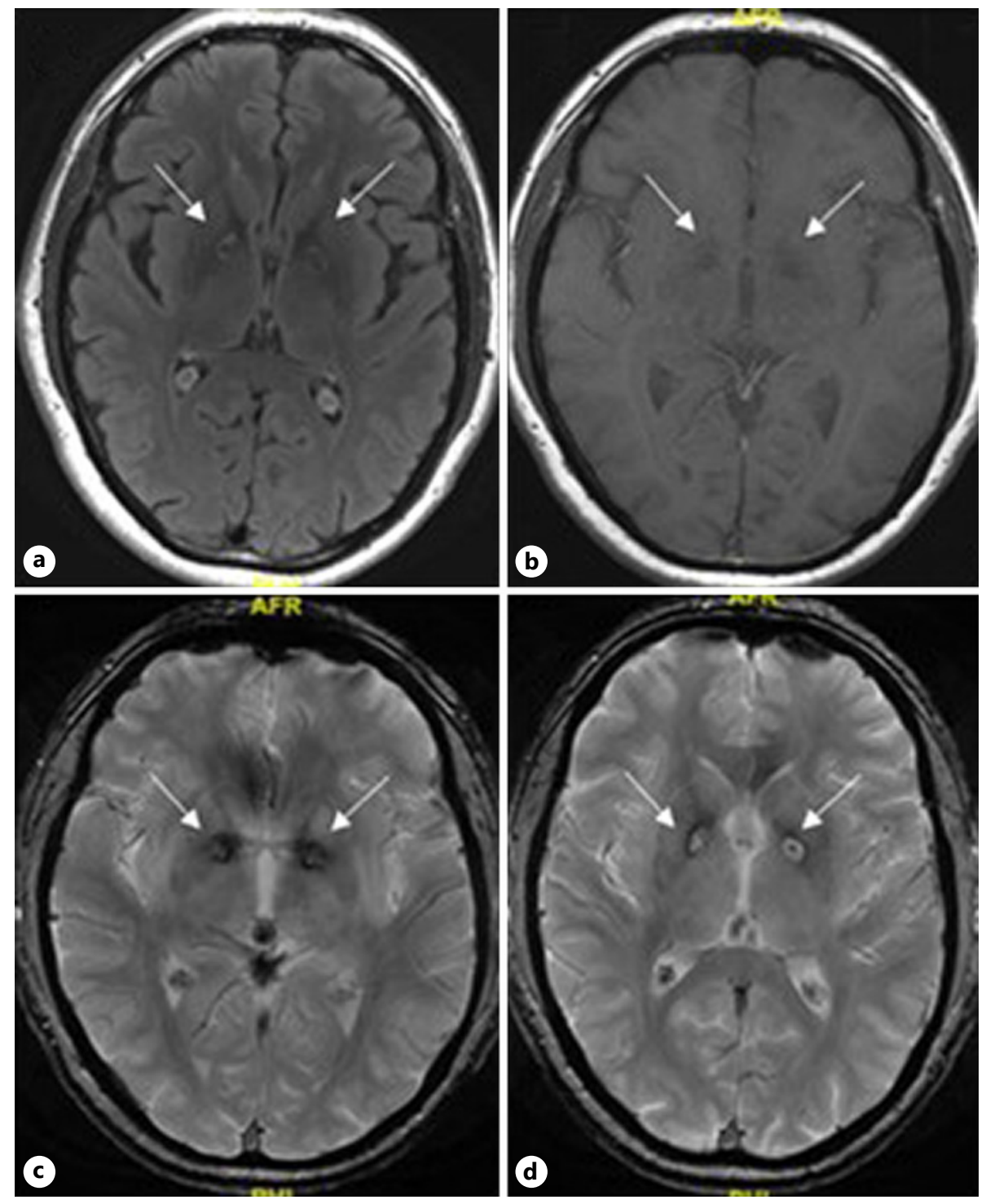

Fig. 2. MRI brain at age 44. Axial T2-FLAIR sequence (a) showing symmetric round high T2 signal lesions within the globus pallidus bilaterally and axial T1 sequence (b) showing symmetric round low T1 signal lesions within the globus pallidus bilaterally. Axial gradient echo sequences $(\mathbf{c}, \mathbf{d})$ showing presumed hemosiderin deposition within the globus pallidus bilaterally.

and has 2 first-degree relatives with typical ChAc. Mutation of intron 46 of the VPS13A gene is expected to disrupt RNA splicing and likely result in absent or disrupted protein product. Donor and acceptor splice site variants typically lead to loss of protein function [3], and loss-of-function variants in VPS13A are known to be pathogenic [4, 5]. Nevertheless, his normal creatine kinase and red blood cell morphology, normal Western blot, lack of caudate atrophy, absence of choreiform movements, lip/tongue biting, and feeding dystonia are inconsistent with typical ChAc. Regarding the normal Western blot analysis, perhaps chorein production was suppressed to levels sufficient to cause pathogenesis or perhaps posttranslational protein modification occurred. Finally, prominent parkinsonism occurs only in a minority of ChAc patients [2] and could be better explained by early onset Parkinson's disease (PD). 
In several studies, the prevalence of PARK2 heterozygous variants is higher in PD patients [6-10], implying that PARK2 heterozygosity may increase susceptibility for developing PD [11]. PD may, in part, be an oligogenic disorder with individually innocuous mutations of several genes interacting to increase susceptibility to neurodegeneration [12]. Despite the mutant PARK2 allele, however, our patient had intact nigrostriatal innervation based on dopamine transporter scan, pallidal pathology very atypical for PD, and levodopa nonresponsive symptoms.

We arrived at a tentative diagnosis of atypical NA. Additional research is needed to fully uncover the genotypic and phenotypic diversity of ChAc. Tomiyasu and colleagues [5] performed exome sequencing on 35 ChAc patients, among whom they identified 36 different pathogenic VPS13A mutations. A more recent study performed by the same group identified eleven additional novel VPS13A pathogenic mutations [13]. By continuing to study the genotype-phenotype correlations, we will begin to better understand and ultimately improve diagnosis and treatment of this debilitating disease.

Two recent reports describe separate patients with ChAc found to have compound heterozygous VPS13A deletions [14,15]. Perhaps exome sequencing in our patient missed an additional VPS13A variant allele. Whole-exome sequencing sensitivity may be limited by DNA quality, base pair size of deletions/insertions, inability to detect translocations and mosaic/somatic events, and exclusion of certain exons or genes due to quality standards of the performing company. Alternatives are that this patient is a unique case of dual haploinsufficiency secondary to one mutant VPS13A allele and the PARK2 deletion mutation. Our patient's phenotype does not fit well into either a diagnosis of typical early onset PD or typical ChAc. Although speculative, his double heterozygote state may be the etiology of this disorder. Perhaps the 2 genes could function in the same pathway, or perhaps it is a cumulative effect of general cell stress. More research is needed to fully understand the roles of epistatic interactions on phenotypic expression of neurodegenerative disease.

\section{Acknowledgement}

We would like to thank our patient and his family for allowing us to share his case.

\section{Statement of Ethics}

Institutional review was not necessary for this work. Written informed consent was obtained from the patient for publication of this case report and any accompanying images.

\section{Conflict of Interest Statement}

The authors declare that there are no conflicts of interest relevant to this work.

\section{Funding Sources}

The authors declare that no specific funding was received for this work.

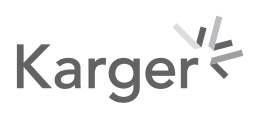




\section{Case Reports in Neurology}

\begin{tabular}{l|l}
\hline Case Rep Neurol 2021;13:341-346 \\
\hline DOI: 10.1159/000515805 & $\begin{array}{l}\text { ○ 2021 The Author(s). Published by S. Karger AG, Basel } \\
\text { www.karger.com/crn }\end{array}$ \\
\hline
\end{tabular}

Mitchell et al.: Heterozygous VPS13A and PARK2 Mutations

\section{Author Contributions}

Steven D. Mitchell, DO: manuscript preparation: writing of first draft and revisions. Roger L. Albin, MD: manuscript preparation: review and critique. William T. Dauer, MD: manuscript preparation: review and critique. John L. Goudreau, DO, PhD: manuscript preparation: review and critique. Christos Sidiropoulos, MD: manuscript preparation: review and critique.

\section{References}

1 Walker RH, Jung HH, Dobson-Stone C, Rampoldi L, Sano A, Tison F, et al. Neurologic phenotypes associated with acanthocytosis. Neurology. 2007;68(2):92-8.

2 Jung HH, Danek A, Walker RH. Neuroacanthocytosis syndromes. Orphanet J Rare Dis. 2011;6:68.

3 Baralle D, Baralle M. Splicing in action: assessing disease causing sequence changes. J Med Genet. 2005 Oct; 42(10):737-48.

4 Dobson-Stone C, Danek A, Rampoldi L, Chalmers RM, Wood NW, Bohlega S, et al. Mutational spectrum of the CHAC gene in patients with chorea-acanthocytosis. Eur J Hum Genet. 2002 Nov;10(11):773-81.

5 Tomiyasu A, Nakamura M, Ichiba M, Ueno S, Saiki S, Morimoto M, et al. Novel pathogenic mutations and copy number variations in the VPS13A Gene in patients with chorea-acanthocytosis. Am J Med Genet B Neuropsychiatr Genet. 2011;156B:620-31.

6 Brooks J, Ding J, Simon-Sanchez J, Paisan-Ruiz C, Singleton AB, Scholz SW. Parkin and PINK1 mutations in early-onset Parkinson's disease: comprehensive screening in publicly available cases and control.J Med Genet. 2009;46:375-81.

7 Clark LN, Afridi S, Karlins E, Wang Y, Mejia-Santana H, Harris J, et al. Case-control study of the parkin gene in early-onset Parkinson disease. Arch Neurol. 2006;63:548-52.

8 Lesage S, Lohmann E, Tison F, Durif F, Durr A, Brice A. Rare heterozygous parkin variants in French early-onset Parkinson disease patients and controls. J Med Genet. 2008;45:43-6.

9 Nuytemans K, Meeus B, Crosiers D, Brouwers N, Goossens D, Engelborghs S, et al. Relative contribution of simple mutations vs. copy number variations in five Parkinson disease genes in the Belgian population. Hum Mutat. 2009;30:1054-61.

10 Sun M, Latourelle JC, Wooten GF, Lew MF, Klein C, Shill HA, et al. Influence of heterozygosity for parkin mutation on onset age in familial Parkinson disease: the GenePD study. Arch Neurol. 2006;63:826-32.

11 Nuytemans K, Theuns J, Cruts M, Van Broeckhoven C. Genetic etiology of Parkinson disease associated with mutations in the SNCA, PARK2, PINK1, PARK7, and LRRK2 genes: a mutation update. Hum Mutat. 2010;31(7): 763-80.

12 Lubbe SJ, Escott-Price V, Gibbs JR, Nalls MA, Bras J, Price TR, et al. Additional rare variant analysis in Parkinson's disease cases with and without known pathogenic mutations: evidence for oligogenic inheritance. Hum Mol Genet. 2016;25(24):5483-9.

13 Nishida Y, Nakamura M, Urata Y, Kasamo K, Hiwatashi H, Yokoyama I, et al. Novel pathogenic VPS13A gene mutations in Japanese patients with chorea-acanthocytosis. Neurol Genet. 2019;5(3):e332.

14 Spieler D, Velayos-Baeza A, Mühlbäck A, Castrop F, Maegerlein C, Slotta-Huspenina J, et al. Identification of two compound heterozygous VPS13A large deletions in chorea-acanthocytosis only by protein and quantitative DNA analysis. Mol Genet Genomic Med. 2020;8(9):e1179.

15 Verkkoniemi-Ahola A, Kuuluvainen L, Kivirikko S, Myllykangas L, Pöyhönen M. Chorea-acanthocytosis associated with two novel heterozygous mutations in the VPS13A gene. J Neurol Sci. 2020;408:116555. 